\title{
Head trauma on cruise ships
}

\section{Eilif Dahl}

Department of Occupational Health, Haukeland University Hospital, the Norwegian Centre for Maritime Medicine, Bergen, Norway

Head injuries, like acute chest pain, are feared emergencies at sea [1]. Most cases are not serious, but while there are fairly good diagnostic and therapeutic possibilities for patients with worsening chest pain on most cruise vessels, not much can be done aboard for a deteriorating head injury patient. Urgent evacuation to a modern neurosurgical unit ashore is the key to success, but that is not always possible [2].

In this issue of "International Maritime Health" there are 3 papers that deal with various aspects that complicate evaluation of head trauma on different cruise ships [3-5]. There are practical lessons to be learned from all of them:

1. One head injury case, which initially seemed very serious, turned out to be minor, causing false alarm [3]. The most disturbing symptom, anisocoria, happened when scopolamine from a transdermal patch inadvertently got into one eye and caused mydriasis. To prevent that, after administration of a scopolamine patch, the hands and the application site should always be washed thoroughly with soap and water and dried. In the absence of other symptoms and with a typical patch history, extensive diagnostic work-up should not be necessary. Only time is needed for the dilated pupil to normalise [3].

2. Another head trauma that happened ashore was initially cleared at the local hospital, but should be "observed for the next 48 hours" [4]. The patient returned to the vessel against the ship's doctor's strong objections. Ahead was a non-stop voyage without any evacuation possibilities for the next 8 days. It doesn't make much sense to observe such a patient aboard where nothing can be done if signs of increasing intracranial pressure develop. Furthermore, in this case delayed suspicion of a cervical fracture could have caused additional harm, but didn't. In cases of doubt, if head injury patients need to be observed, they should stay ashore in - or close to - a neurosurgical unit, until they can be safely repatriated [4].
3. The third head injury is reported in a paper discussing a court decision from 2014 stating that a ship owner can be held vicariously liable for the negligence of medical staff directed at the ship's passengers [5]. In short, an elderly male cruise passenger fell and hit his head when entering a trolley ashore in Bermuda. He got back to the ship, was seen briefly by the on-duty nurse who found him well enough to let him recover in his stateroom. Later he felt worse and returned to the medical facility aboard. The doctor, who saw him about 4 hours after his first visit, quickly admitted him to a hospital ashore in Bermuda, from where he was evacuated to New York the next day. He died one week later [6]. The patient's daughter brought a malpractice claim, but from a ship's doctor's point of view (see case \#2 [4]) the case was handled well: The nurse's initial evaluation was minor head trauma. When the passenger got worse some hours later, he was seen by the ship's doctor who understood that the case exceeded the ship's capabilities and promptly had him hospitalised, instead of observing him aboard a vessel heading for New York.

Some of the challenges for medical staff when dealing with head trauma on cruise ships are lack of communication, misunderstandings, unrealistic expectations and patients' non-compliance with medical advice regarding medical disembarkation. A small percentage of head trauma patients who are initially asymptomatic or have only mild symptoms will need urgent neurosurgical intervention ashore [7]. Therefore medical staff should emphasize to head trauma patients before releasing them that they must immediately report back if feeling any worse, and in particular not wait until the vessel has left port.

In every head injury case ship's medical staff faces crucial questions: how safe is safe enough? Is the risk of something bad low enough that it is reasonable to neglect it [8]? And if the clinical situation deteriorates, how fast can the patient get ashore? 


\section{CONFLICTS OF INTEREST}

No financial or material support received. The author has worked as independent ship's doctor and medical consultant for many cruise companies. Views expressed in this article are those of the author and do not reflect the views and opinions of other cruise doctors, cruise companies, the Norwegian Centre for Maritime Medicine or the editorial board of International Maritime Health.

\section{REFERENCES}

1. Dahl E. Acute chest pain on cruise ships. Int Marit Health 2015; 66: 4-5.

2. Williams S, Dahl E. Briefing notes on emergency medical disembarks by helicopter at sea in North America. Int Marit Health 2014; 65 : $7-12$.
3. Dahl E. Head injury and anisocoria on a cruise ship. Int Marit Health 2016; 67: 159-160.

4. Dahl E. Head injury in a cruise passenger during a shore excursion. Int Marit Health 2016; 67: 161-162.

5. Dahl E. Cruise ship's doctors - company employees or independent contractors? Int Marit Health 2016; 67: 153-158.

6. “Franza v. RCL". The United States Court of Appeals, Eleventh Circuit. Case No. 13-13067, filed 11/10/2014. http://media.ca11. uscourts.gov/opinions/pub/files/201313067.pdf.

7. Papa, L, Stiell, IG, Clement et al. Performance of the Canadian CT head rule and the New Orleans criteria for predicting any traumatic intracranial injury on computed tomography in a united states level I trauma center. Academic Emerg Med 2012; 19: 2-10.

8. Wears RL. Risky business. Ann Emerg Med 2014; 64: 137-139. 